\title{
Acquisition of English Language Prepositions in the Absence of Formal Grammar Teaching
}

\author{
Beena Sudhakaran ${ }^{1}$ \\ 1 English Language Department, Centre for Languages and Pre-University Academic Development (CELPAD), \\ International Islamic University Malaysia \\ Correspondence: Beena Sudhakaran, English Language Department, CELPAD, International University Malaysia, \\ Jalan University, Petaling Jaya, Selangor, Malaysia. Tel: 60-1-3389-4815
}

Received: November 26, 2015

Accepted: December 11, 2015

Online Published: December 16, 2015

doi:10.5430/elr.v4n4p88

URL: http://dx.doi.org/10.5430/elr.v4n4p88

\begin{abstract}
An oft-debated issue is whether or not English grammar has to be taught formally. One group insists that students will not be able to learn grammar unless they are taught formal grammar rules, while the other maintains that students will pick up grammar on their own in due course.

To determine the extent of acquisition of English prepositions in the absence of formal teaching of prepositions, a longitudinal study was carried out on a single matriculation student. Data was collected on the errors in the use of prepositions in various speaking and writing tasks - essays, journals, interviews and presentations - at six monthly intervals, over a period of two years. An analysis of the student's use of prepositions was carried out to determine whether or not there had been any changes over this period.

The results of this study show that there were indeed improvements in the use of prepositions by this student for both speaking and writing tasks. Regarding the types of errors, there were more errors of commission than errors of omission. A common error was the unnecessary use of the phrase involving a preposition, 'for me'. With respect to the progress made, in speaking tasks, most improvement was seen in the prepositions 'for', 'in' and 'about', while in writing tasks, the best results were with the prepositions 'to, 'of' and 'in'.

These findings imply that, grammar should be taught in a way that is compatible with the natural processes of acquisition, rather than with the use of formal grammar rules.
\end{abstract}

Keywords: Prepositions, Natural acquisition, Second language acquisition

\section{Introduction}

\subsection{Background to the Study}

Second language acquisition (SLA) or the learning of a language other than the mother tongue, can be either through formal teaching, or it can take place through exposure to the use of the language (Gass \& Selinker, 2001). Learning can be influenced by factors like complexity and abstractness of the language (Gass, Torres, \& Jose, 2005). While engaged in meaning-focused lessons, it was found that focus on form-assisted learning improved linguistic accuracy (Loewen, 2005). Grammar may need to be emphasized in situations where the linguistic skills of learners do not allow them to either process the input, or to re-formulate that content (Meyer, 1995).

The use of the communicative approach in second language teaching and learning changed the emphasis from form to meaning. This resulted in reduced emphasis on grammar with less focus on linguistic forms (Nassaji, 2000). The emphasis in language learning also changed, with rapid learning in activities that required a negotiation of meaning as compared to acquisition (Nassaji, 2000). It has also been found that second language was not learned through conversational interaction, because while the learners needed the language to communicate, they also had to communicate to learn the language (Norton, 2000; Bremer et al, 1996). Another view is that naturalistic language acquisition situations rely more on associative memory, with less emphasis on grammar. There appears to be better implicit learning when there is more time and the pattern of grammatical morphemes is not so crucial (DeKeyser, 2005).

There has been considerable debate on the most effective form of grammar instruction in the communicative classroom (Doughty \& Williams, 1998; Lightbown, 2000; Norris \& Ortega, 2000). It has been pointed out that the communicative 
approach is based on the assumption that learners need not be taught grammar to enable communication, but, rather, grammar will be acquired naturally as part of the process of learning to communicate. Thus, in much of communicative language teaching, grammar is not taught directly (Ellis, 1997). In the naturalistic context, on the other hand, there is no formal instruction, so that the learner has to rely on his background knowledge and intuition. However, because the quantity and quality of the input is affected by many factors, exposure to the target language may not be as much as expected (Norton, 2000; Goldstein, 2001). L2 also plays a role in language acquisition, where the extent of acquisition of the language depends on L2 proficiency (Zhang \& Widyastuti, 2010).

Differing views have been expressed by others. One study found no differences in the accuracy of grammatical morphemes in both formal classroom instruction and natural acquisition (Pica, 1983). Another study on the acquisition of the English article system concluded that only a few subjects reached high levels of expertise (Gorokhova, 1990). The communicative approach was also found not to work well in countries where English is a second language, because there was insufficient structure for the language to allow the message to get across (Roberts, 1995). It has also been suggested that grammar should not be taught in isolation for its own sake, but as social function and as discourse (Celce-Murcia \& Hills, 1988). Besides, too much emphasis on grammar also distracts learners, while it may not even be relevant for them (Celce-Murcia, 1991). Another view disputing the teaching of grammar is that teachers may be so bent on correcting mistakes that they fail to realize that the main objective of learning the language is to be able to function in society (Crismore, Ngeow \& Soo, 1996). It has also been suggested that the learning of a language may take place unconsciously (Selinker \& Lamendella, 1981).

There is also a view that language acquisition can be enhanced up by explicit instruction (Ellis, 2002). Formal instruction has been said to be 'consciousness raising' (Ellis, 1990; Schmidt, 1990). This has been supported by others (Govindasamy, 1994), who suggest that 'consciousness raising' or imparting the formal properties of language, assists language learning. It has been pointed out that grammatical consciousness or developing knowledge of grammatical features of a language, has been used more than a thousand years ago as a pedagogic tool in the study of Latin grammar (Rutherford \& Smith, 1998).

With respect to Malaysian ESL learners, it has been found that the frequency of uptake and the degree of success in grammar proficiency depends on factors like linguistic focus, complexity, type of feedback, as well as source and direction of form focused instruction (Ismail, 2005). A study on Malay ESL college students found that with instruction, the clarity as well as the coherence of their language improved (Govindasamy, 1994). With respect to prepositions, it was found that the preposition system posed persistent difficulties to Malaysian students (Mohideen, 1991). It was also found that wrongly used prepositions could be minimized through error identification drills (Ruziah, 2006). Another study showed that learners were better at English locational prepositions as compared to directional prepositions (Wong \& Chong, 2006).

With respect to the acquisition of prepositions, the main cause of the difficulties faced by ESL learners is their wrong understanding of prepositions (Lindstromberg, 1991). The usage of spatial prepositions was found to access a different semantic representation as compared to the locative prepositions (Sandra \& Rice, 1995). It has also been pointed out that the sequence in which prepositions are acquired is independent of whether or not they have received formal language instruction, as well as of age and the learner's mother tongue (Dulay \& Burt, 1974; Dulay \& Burt, 1973; Bailey, Madden \& Krashen, 1974).

Looking next at the assessing of competence in the use of prepositions, the most commonly used method is error analysis, this having played a major role in research on L2 acquisition (Gorokhova, 1990). These can be errors of commission, defined as when action was not warranted, actively doing something wrong, or errors of omission, defined as not acting when action was warranted, or failing to actively do something right (Wagner \& Weitzman, 2015). It has been pointed out that errors in the use of language may not be due to problems pertaining to rules of grammar like not knowing, forgetting, or, not paying attention to them (Schmidt, 1990). A combination of the native and target languages may contribute to errors (Duskova, 1983), in addition to developmental factors (Schumann, 1979). To determine L2 acquisition, it has been suggested that this can be carried out through an analysis of the types of errors made by learners and how these errors change over time. The stages in the acquisition of specific grammatical features can be identified towards working out developmental patterns (Ellis, 1997). Errors in spoken, informal language are more difficult to spot than written, formal texts. This may be due to the fact that conversational speech is transient, usually spontaneous (Kramsch, 1998).

\subsection{Statement of the Problem}

In Malaysia, English was the language of administration and the medium of instruction in schools up till independence in 1957, and for about a decade after that. When the National Language Policy was implemented in 1967, the national 
language, Bahasa Malaysia (BM), replaced English as the premier language of the nation, and the English language was no longer the main medium of instruction. This move has had implications for the ESL situation in Malaysia. Apart from this, there were also changes in grammar teaching, where the communicative approach was adopted instead of the emphasis on language structure. Thus, grammar was integrated with listening, speaking, reading and writing instead of teaching the notions and functions of grammar. Consequently, there was a deterioration of students' grammar skills. There are three major ethnic communities in Malaysia - the Malays, Chinese and Indians. With respect to aspects of grammar like tenses, one reason for the difficulties faced by Malays in acquiring them is that there is no tense system in the Malay language (Asmah, 2000). Apart from this, due to the cross-fertilization between Malay, English and the various ethnic languages like Mandarin and Tamil in urban Malaysia, there are many variations in English (Gill, 1993). Thus, it has been contended that there was a need for greater emphasis on English language instruction in Malaysian schools (Kaur, 1995).

\subsection{Purpose of the Study}

This study focuses on determining the degree of acquisition of English prepositions by Malay ESL learners, in the absence of formal grammar teaching.

\section{Theoretical Framework}

While there has been much debate and analysis on the theories of second language acquisition through naturalistic learning, there has been little scientific analysis carried out. For a quantitative study of naturalistic acquisition, the patterns of errors of learners have to be studied over a protracted period of time. This study adopted the semiotics-based methodology first used in Saussure and his Structuralist Paradigm, later modified into the sign-oriented framework by Tobin and Reid. The specific use of concrete language data obtained from spoken discourse and written tasks in differing linguistic and situational contexts was studied. In this study, actual language samples were analysed to observe patterns of use. The various stages in the analysis indicate how a system is discovered as depicted in the Figure below:

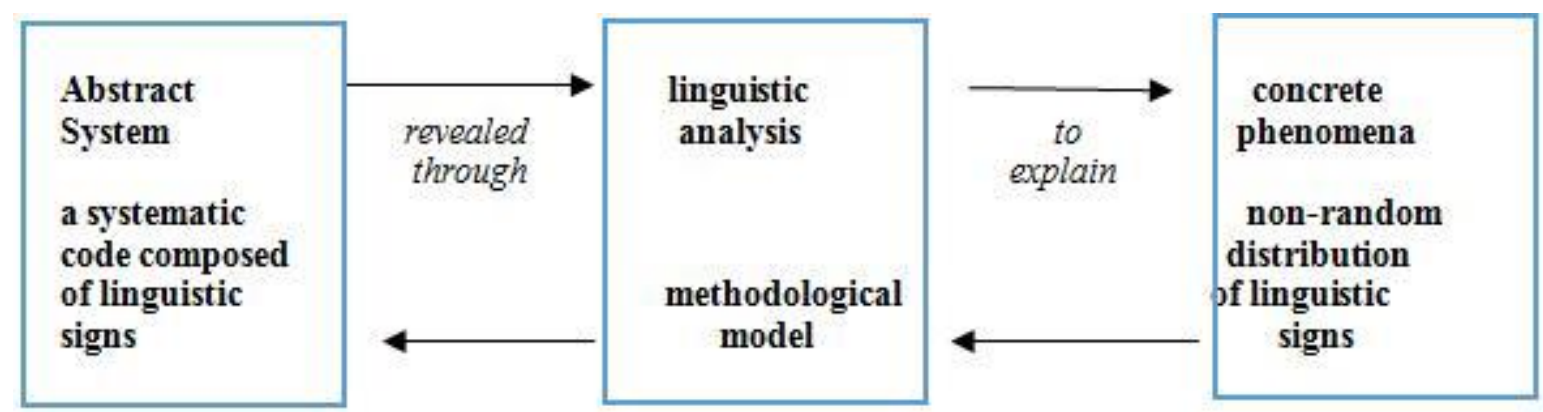

Figure 1. The sign-oriented framework (adapted from Tobin, 1990, p. 48)

The theoretical considerations and the sign-oriented framework were used to develop an analytic framework shown in Table 1 below.

Table 1. Framework of the study

\begin{tabular}{|c|c|c|c|c|}
\hline Abstract system & \multicolumn{4}{|c|}{ Analysis of concrete phenomena } \\
\hline & $\begin{array}{l}\text { Core value of } \\
\text { system }\end{array}$ & \multicolumn{3}{|c|}{ Misunderstanding of core value of the system } \\
\hline \multirow[t]{5}{*}{ Prepositions } & Correct use of & \multicolumn{3}{|c|}{ Misunderstanding and errors: } \\
\hline & & \multicolumn{3}{|c|}{ Errors in use of prepositions } \\
\hline & & $\begin{array}{l}\text { Prepositions inserted } \\
\text { where not needed }\end{array}$ & $\begin{array}{l}\text { Incorrect } \\
\text { prepositions } \\
\text { used }\end{array}$ & $\begin{array}{l}\text { Prepositions } \\
\text { missed }\end{array}$ \\
\hline & Coherent & \multicolumn{3}{|c|}{ Incoherent message } \\
\hline & message & \multicolumn{2}{|c|}{ Errors of commission } & $\begin{array}{l}\text { Errors of } \\
\text { omission }\end{array}$ \\
\hline
\end{tabular}


The above framework was used to analyze the data on the degree of accuracy of the use of prepositions collected over the period of the study, as well as analysis of the different types of errors.

\section{Methodology}

This case study uses an exploratory-quantitative-statistical paradigm, characterised by a non-experimental design, using quantitative data, with subsequent statistical analysis. It uses a longitudinal approach that entails observing the development of linguistic performance over a span of time. This involves analysing the spontaneous speech and written work of the subject to determine whether there are any changes in her use of English prepositions. This technique is in accordance with Tobin's sign-oriented theory which investigates specific use of concrete language data obtained from both spoken and written discourse in different linguistic and situational contexts. Thus, this study focuses on the acquisition of prepositions by a Malay ESL learner in the naturalistic context without formal instruction, by noting whether there is any improvement in her use of prepositions over the period of study.

\subsection{The Sample}

The sample for this study was a randomly picked Malay student from a Malaysian public school (where the medium of instruction is Malay), who had joined International Islamic University Malaysia (IIUM) for matriculation. At the time of commencement of the study, she was studying English prior to taking up a major at the main campus. Her class was co-educational and the average age of the students in her class was 19 years.

This student had previously been taught the English language as a second language using a communicative approach, without being taught formal rules of grammar, during her eleven years of schooling, before she joined the Matriculation programme at IIUM. For the duration of eight months in the Matriculation course, students in her class were taught grammar in an integrated manner with listening, speaking, reading and writing skills. Grammar rules were, again, not introduced. In IIUM, the medium of instruction is English, and students have opportunities to interact in English with international students, especially when they move to the main campus to pursue their majors, on completion of their matriculation programme. These international students are second language learners with a variety of L1 backgrounds. Some of them have a high level of proficiency while the majority has a moderate proficiency in English. However, they are able to converse well in English. In addition, while this student underwent formal instruction in English for a period of eight months, she was not taught prepositions, so that any improvement in skills in the use of prepositions would have been achieved through her own efforts in reading and communicating in English with international students, lecturers and others.

A combination of the naturalistic type of data collection and deliberate data collection was used in this study. The student was asked if she would like to be a participant in a language-based research. She was not given precise information on what grammar forms were being studied. This was to avoid over-sensitising her to the particular feature. Thus, she was encouraged to behave as naturally as possible, especially during the oral sessions, and did her usual work in written assignments.

Data collection was divided into five phases - apart from the baseline data, another four sets of data were collected at six monthly intervals as shown in Table 2 below.

Table 2. Phases of data collection

\begin{tabular}{lccccc}
\hline $\begin{array}{l}\text { Data collection } \\
\text { Set }\end{array}$ & $\begin{array}{c}\text { Baseline data } \\
\left(1^{\text {st }} \text { set }\right)\end{array}$ & $\begin{array}{c}2 \\
\left(2^{\text {nd }} \text { set }\right)\end{array}$ & $\begin{array}{c}3 \\
\left(3^{\text {rd }} \text { set }\right)\end{array}$ & $\begin{array}{c}4 \\
\left(4^{\text {th }} \text { set }\right)\end{array}$ & $\begin{array}{c}5 \\
\left(5^{\text {th }} \text { set }\right)\end{array}$ \\
\hline Time elapsed & 0 & 6 months & 12 months & 18 months & 24 months \\
\hline
\end{tabular}

At each session, data was collected from essays, journals, interviews and presentations as explained below.

\subsection{Instrumentation}

The productive aspects that were focused on were writing and speaking. To elicit information on preposition use by the student, two oral and two written tasks were utilized. The first oral-based task consisted of an interview with the student, while the other was an oral presentation. The written tasks consisted of five essays, and fifteen journal entries each time. As mentioned above, there were five phases - first, an initial round where the student carried out the four tasks: interviews, essays, journal entries, and presentations, followed by subsequent rounds of the same tasks, at six monthly intervals. At each phase, data was obtained on the tasks in the form of individual pieces of information obtained for analysis of each separate task. 


\subsubsection{Interviews}

Interviews were conducted in three parts - the first part involved a question-answer session confined to personal areas; subsequently, the student was asked general questions on a given topic, while the last part consisted of academic related questions. The total duration of the interviews was standardised at five minutes. The first session focused on areas that were important to the student. The second session consisted of areas familiar to the student and concerned her feelings, perceptions, or attitudes. In the final session, she was provided different contexts to induce her to use prepositions. The focus on familiar areas was to encourage her to speak spontaneously. At the same time, the focus had to appear to be not on any specific area of grammar, so that the student was not made aware that the study was on her use of prepositions. From the student's responses, while it may be impossible to make very clear and conclusive judgments about aspects that were important to the student, general assumptions would have to be made that some questions would elicit more important information. There is a possibility that the degree of accuracy may vary with the areas being discussed. These interviews were recorded, and subsequently transcribed for analysis

\subsubsection{Presentations}

The student was asked to make a presentation on a specific topic, without any prior preparation, for about five minutes. While the student was not forewarned on the topic, the same topic was used each time. This would assist in gauging the progress of the student in the use of prepositions, and also served to eliminate biases that could arise from using different topics. These presentations were also recorded, transcribed, and, subsequently analysed.

\subsubsection{Essays}

The student was required to write five essays of about 400 words at six monthly intervals. She was allowed to choose any topic for the essay, but to forestall any prior preparation for the essay, she was not told of the task in store for her until she arrived. These essays too were analyzed for errors related to the use of prepositions.

\subsubsection{Journal Writing}

Journal writing had been part of the routine in class. The journal entries were submitted to the teacher weekly, but were never corrected or graded. The teacher would read every journal entry and take appropriate action on the grouses, questions and concerns raised by students. It was generally regarded as a means by which students communicate with teachers on confidential issues, as well as to encourage students who were reluctant to speak in class to communicate freely with teachers.

The student wrote these entries as part of her writing assignments. It was impressed upon the student that journal writing was actually free writing. This was to ensure that the student paid more attention to the content, rather than on writing style or grammar. Consequently, it was hoped that the language used in these journals would be informal, and closer to informal speech. This would provide information on the student's use of prepositions in as natural a setting as possible, without the student making conscious efforts to avoid errors or deliberately writing in a formal manner. The student was required to write fifteen journals every six months, and these were analyzed for errors related to the use of prepositions.

\subsection{Data Analysis}

A frequency count was first carried out of the various instances where prepositions were used, whether correctly or incorrectly. The correct use of prepositions was labelled as coherent messages. On the other hand, the use of prepositions where they were not required, and the use of inappropriate prepositions, were considered as errors of commission. The errors of omission or obligatory contexts were labelled where prepositions were needed but were missed, as shown in the framework of the analysis as in Table 3 below:

Table 3. Framework of data analysis

\begin{tabular}{|l|l|l|l|l|}
\hline Abstract system & \multicolumn{3}{|l|}{ Analysis of concrete phenomena } \\
\hline & Core value of system & Misunderstanding of core value of the system \\
\hline Prepositions & $\begin{array}{l}\text { Correct use of } \\
\text { prepositions }\end{array}$ & $\begin{array}{l}\text { Misunderstanding and errors: } \\
\text { Errors in use of prepositions }\end{array}$ \\
\cline { 3 - 5 } & $\begin{array}{l}\text { Prepositions } \\
\text { inserted where not } \\
\text { needed }\end{array}$ & $\begin{array}{l}\text { Incorrect } \\
\text { prepositions } \\
\text { used }\end{array}$ & $\begin{array}{l}\text { Prepositions } \\
\text { out }\end{array}$ \\
\cline { 2 - 5 } & Coherent message & Errors of commission & Errors of omission \\
\hline
\end{tabular}


To examine the accuracy of production of prepositions, the percentages of errors in the use of prepositions in each six-month period were compared, to determine the differences, if any, among the five sets of data. The errors of omission and commission were also compared to the total number of prepositions used. These errors were analyzed by type of preposition, type of activity, and whether there were differences over time. Such an analysis was carried out for all prepositions in general, for each type of preposition; the process repeated for each set of data. This would provide data on the level of accuracy in the use of prepositions and the trend over time during the study period. Comparisons were also made between writing and speaking tasks, to determine if there were differences in levels of accuracy among these tasks.

To determine the most common source of errors, the different types of errors made by the student with various prepositions for both speaking and writing tasks were identified. The frequencies of errors for each type of error for each speaking and writing tasks were determined. Attempts were also made to identify any alternative mechanisms employed by the student in place of prepositions, and these were further analysed.

To identify the prepositions with which the learner had the most difficulty, in the first part of the analysis, the student's performance in some of the most commonly used prepositions in both speaking and writing tasks was focused upon. From this, the prepositions with the highest number of errors were determined. Apart from this, there was an analysis of clusters of prepositions, based either on similar categories, for example, locational or directional prepositions, or those with broad similarities in meaning for example, 'like' and 'as', or prepositions that are usually considered together for example, 'before' and 'after'.

\section{Results and Discussion}

The proficiency of the student in the use of prepositions ranged from $61.1 \%$ to $71.6 \%$ in speaking tasks and 78.1 to $90.3 \%$ in writing tasks. The errors in the use of prepositions by this student were generally low for both speaking and writing tasks.

\subsection{Errors in Speaking Tasks}

\subsubsection{Presentation}

With respect to spoken discourse in presentation, there were fewer errors in the use of prepositions in the later sets of data as compared to the earlier sets. For example, there was no error of commission in the fourth set of data, and no error of omission in the third and fifth sets of data as seen in Figure 2 below.

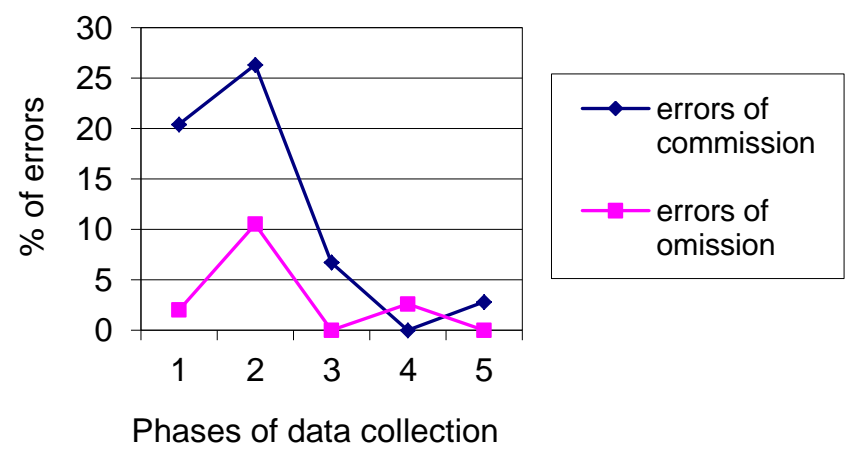

Figure 2. Level of Errors in Presentations

\subsubsection{Interview}

In the next spoken discourse, the interview, a steady level of errors of commission had been maintained in all the five sets of data, despite the fact there had been a drastic increase in the numbers of prepositions used in the fourth and fifth sets of data. Here, there was no error of omission in four sets of data, while one set only had minimal error, as seen in Figure 3 below: 


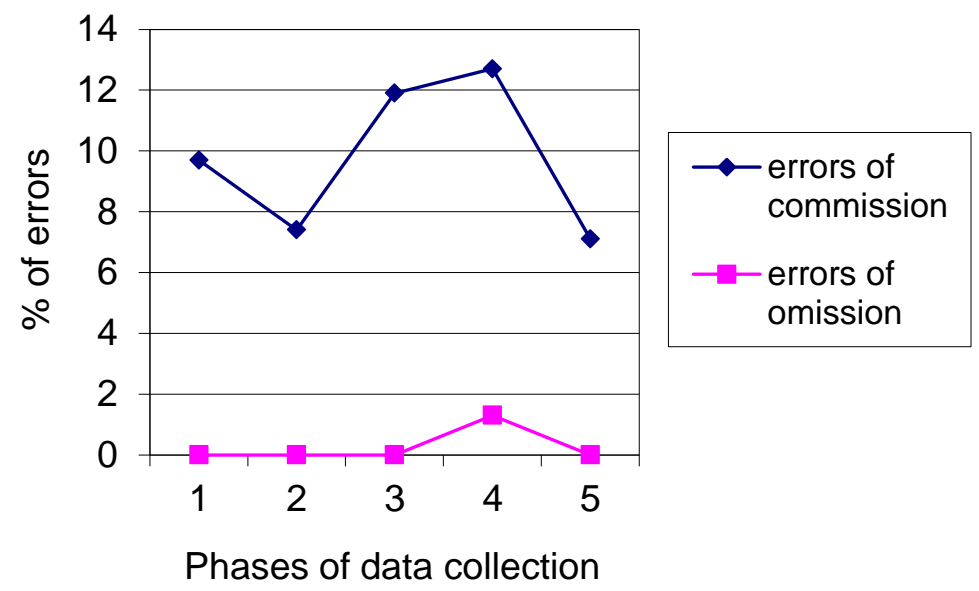

Figure 3. Level of Errors in Interviews

In summary, in speaking tasks, the level of errors in the use of prepositions was low. In general, there seemed to be an improvement in skills in the use of prepositions, with less errors being made in the later sets of data as seen in Figure 4 below.

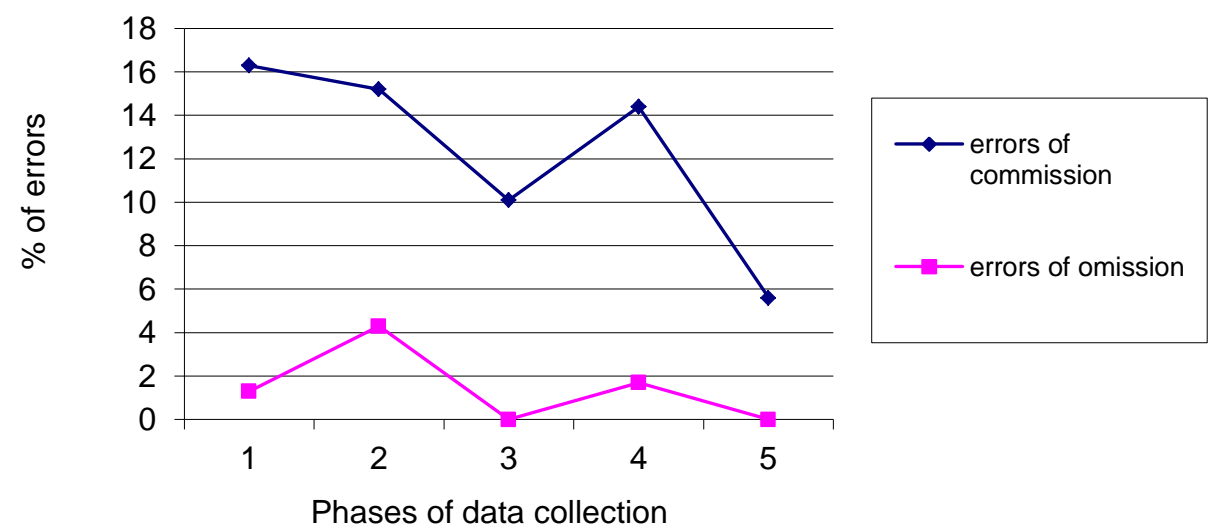

Figure 4. Level of Errors in Speaking Tasks

\subsection{Errors in Writing Tasks}

\subsubsection{Essay Writing}

Considering the written discourse, in essay writing, there were fewer errors of commission in the later sets of data. There were errors of omission only in the first and fifth sets of data as seen in Figure 5 below. 


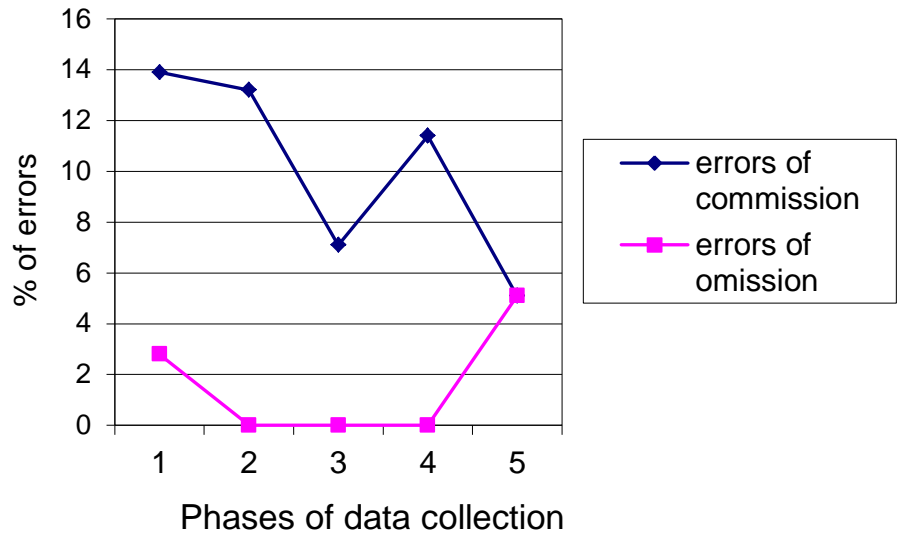

\subsubsection{Journal Writing}

Figure 5. Level of Errors in Essay Writing

Looking at journal writing, again, there was a large decrease in errors of commission after the first set of data with no error of omission in the fifth set of data as seen in Figure 6 below.

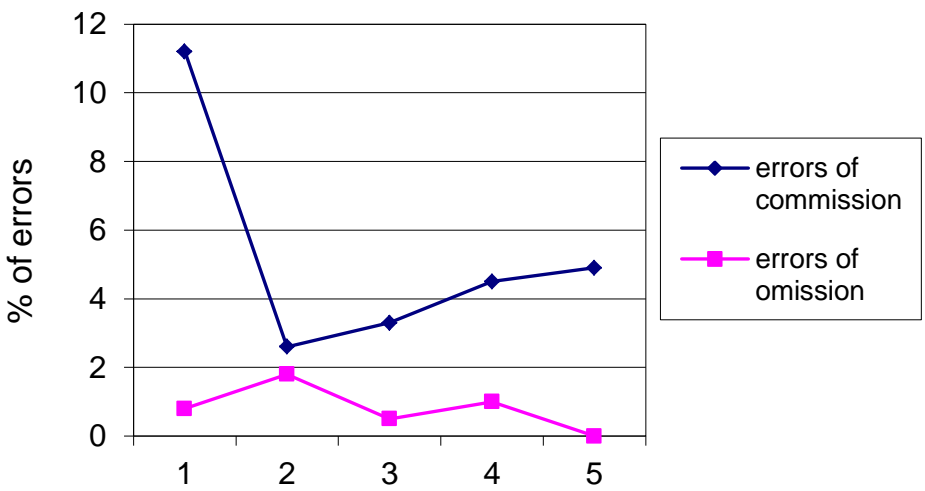

Phases of data collection

Figure 6. Level of Errors in Journals

In summary, in the writing tasks, there was a decrease in errors of commission, while for errors of omission the results were equivocal, and no conclusions could be drawn, as can be seen in Figure 7 below:

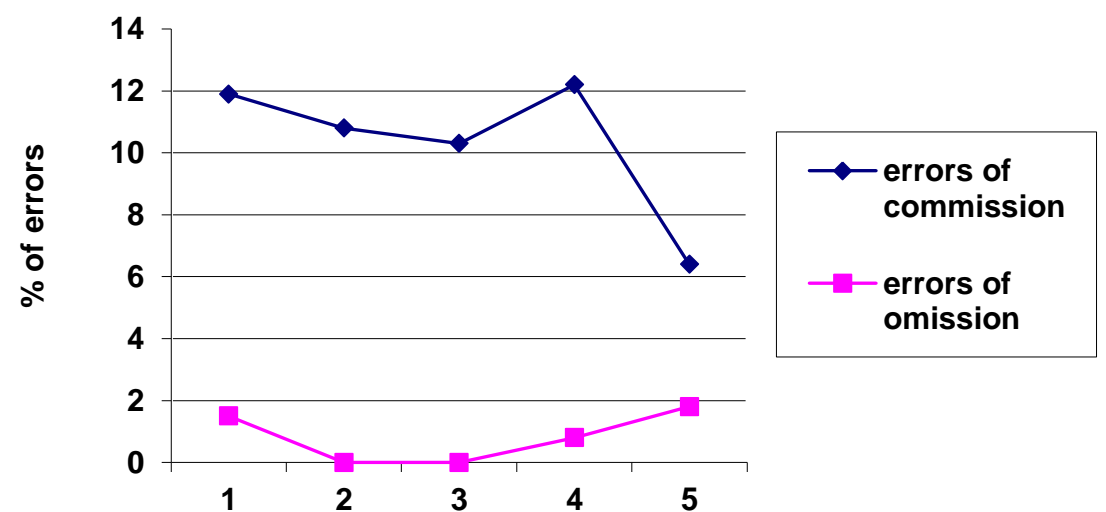

Phases of data collection

Figure 7. Level of Errors in Writing Tasks 
The student appeared to have had more improvement in writing tasks as compared to reading tasks. This could perhaps be explained by the fact that in the speaking tasks, the student did not have the time to reflect, the mode itself being spontaneous, whereas in the written mode, there was an opportunity to reflect and make the necessary corrections. In addition, the prepositions in which the most errors were made differed for writing and speaking tasks, indicating that competence may have been achieved in certain prepositions for writing, but not for speaking.

While there was improvement in the levels of errors, this was, however, nowhere near the competence level of native speakers. It has been argued that there may be less exposure to the target language than expected, because many variables can limit the quantity and quality of input of the target language (Bremer et al., 1996). One reason for this could be that these students tended to confine themselves to their own ethnic group, where they resort to their mother tongue as the language of communication. This lack of contact with foreign students may have deprived them of opportunities to practice the use of the English language. A study by Bremer et al. (1996) did not find that naturalistic contexts gave learners more opportunities for input, since many subjects did not use the target language with colleagues, friends and relatives (Bremer, K., Broeder, P., Roberts, C., Simonet, M., Vasseur, M-T, 1996).

In addition, the student's culture may also have contributed to the errors produced by the subject. It has been pointed out that silence (situations where learners do not speak or write) can be due to 'cultural silence' where people are silent by nature as opposed to the silence of ignorance, Finnish and Japanese learners being examples (James, 1998). A similar situation seems to exist among Malay students who, generally, do not participate actively in class discussions (Mohideen, 1991).

\subsection{Types of Errors in Use of Prepositions}

In speaking tasks in general, there were more errors of commission than errors of omission. For some prepositions there were both errors of commission and errors of omission, i.e. 'at', 'with', 'of' and 'to'.

In the written discourse, the errors of commission were consistently more than the errors of omission over the whole period of study. Again, for seven prepositions, there were both errors of commission and errors of omission, i.e. 'at', 'in', 'about', 'from', 'for', 'of' and 'during'. On the other hand, for the preposition 'to' there were only errors of omission and no errors of commission.

\subsection{Types of Errors in Student's Use of Alternative Locative Frames}

Considering alternative locative frames, this student had the habit of using the phrase 'for me' in situations where its use was not warranted. In addition, she had also used other words instead of prepositions e.g.

"Being a student, I enjoy going for a holiday with friends 'when' (instead of 'during') semester break."

This is an example of transfer of the mother tongue, since in Bahasa Malaysia pada (when) is used in this situation.

\subsection{Pattern of Acquisition of Prepositions}

With respect to a specific pattern in the acquisition of prepositions, she seemed to find some prepositions easier than others and consequently acquired them earlier. Considering her performances in the most commonly used prepositions, there were differences in writing and speaking tasks.

In the speaking tasks, the best improvement was seen in the prepositions 'for', 'in' and 'about', whereas, in the writing tasks, the prepositions 'to, 'of' and 'in' were among those with the best results. On the other hand, the most common errors in the use of prepositions in the speaking tasks were with 'in', followed by 'for' and 'at', while in the written tasks, the most common errors were with 'at', followed by 'in' and 'about'.

In the analysis, it can be seen that particular prepositions were more easily acquired than others. There were instances where there were no errors of omission and minimal errors of commission in certain sets of data, so that it appeared that errors of commission were produced at a higher level. This indicates staged development, another feature of SLA (Mitchell \& Myles, 2004). Apart from this, since the actual numbers of errors of omission were low, improvement over the study period could not always be demonstrated clearly.

\subsection{Acquisition of Prepositions in the Naturalistic Setting}

Considering next the extent to which this student acquired prepositions in the informal setting, it can be concluded that there were improvements in the use of prepositions over the period of study for both the speaking and writing tasks. While competency levels of this student in her use of prepositions had improved, her overall competency was still not of a very high level, and fell short of the competency level that would be achieved by native speakers of English. 
Some studies by other researchers have shown that the ability to communicate in a second language may not necessarily ensure competence in that language. One such study failed to show much acquisition of grammar, despite the subject being able to communicate enough to fulfill his requirements (Schmidt, 1983).

It needs also to be pointed out that the level of competence in the use of prepositions may not also be representative of the competence in that language. This means that even if a subject has a high level of competence in the use of prepositions, he may not have a high level of competence in that language. In addition, many researchers found that there were particular types of grammatical items including prepositions, which learners failed to acquire. It was also found that even in advanced ESL learners, errors were morphological rather than syntactic, indicating that learners were not competent in the use of grammar (Ellis, 1997).

\subsection{Limitations of Study}

This was a case study carried out only on one student and may not be representative of the population. A case study has been described as one which centres on a single individual or a limited number of individuals, documenting some aspects of their language, usually over an extended period of time (Nunan, 1992). One such study was conducted with a Japanese painter called Wes, over a three-year period, which concluded that there was not much development in grammar, despite being able to communicate well enough to fulfill his requirements (Schmidt, 1983).

\section{Conclusion}

It can be concluded that there were improvements in the use of prepositions over the period of study for both speaking and writing tasks. These findings indicate that there is a need to equip teachers with special skills to be able to teach prepositions in a way that is compatible with the natural processes of acquisition. The emphasis should be on developing implicit knowledge of the L2, without neglecting explicit knowledge. It has also been pointed out that since some grammatical features are acquired naturally, while others are not, there may be a need for form-focused instruction to assist learners in those areas where difficulties are faced (Ellis, 1997).

A task-based or task-supported approach would allow students to concentrate on the meanings of lexical items or of specific grammatical structures. Learners should also be developmentally ready to acquire prepositions. It needs to be borne in mind that there is also considerable variability in the rate of learning and in the ultimate level of achievement.

\section{References}

Asmah Haji Omar. (2000). Time in Malay Grammar: English in Malaysia: A Typology of its Status and Role. In Chan Swee Heng, Mohammad A. Quayum, Rosli Talif (ed) Diverse Voices: Readings in Languages, Literatures and Cultures, pp. 22-34. Serdang: University Putra Malaysia Press.

Bailey, N., Madden, C., \& Krashen, S. (1974). Is there a "natural sequence" in adult second language? Language Learning, 24, pp.235-243. http://dx.doi.org/10.1111/j.1467-1770.1974.tb00505.x

Bremer, K., Broeder, P., Roberts, C., Simonet, M., \& Vasseur, M-T. (1996). Achieving understanding: Discourse in intercultural encounters. London: Longman.

Celce-Murcia, M, \& Hills, S. (1988). Techniques and resources in teaching grammar: Teaching techniques in English as a second language. Oxford: Oxford University Press.

Celce-Murcia, M. (1991). Grammar pedagogy in second and foreign language teaching. TESOL Quarterly, 25, 3, pp.459-478. http://dx.doi.org/10.2307/3586980

Crismore, A; Ngeow K.Y, \& Soo, K. (1996). Attitudes towards English in Malaysia. World Englishes, 15, 3, pp.319-335. http://dx.doi.org/10.1111/j.1467-971X.1996.tb00118.x

DeKeyser, R.M. (2005). What makes learning second-language grammar difficult? A review of issues. Language Learning. Vol 55, Supplement 1. University of Michigan, Michigan, pp.1-18. http://dx.doi.org/10.1111/j.0023-8333.2005.00294.x

Doughty, C., \& Williams, J. (1998). Focus on form in classroom second language acquisition. Cambridge: Cambridge University Press.

Dulay, H. \& Burt, M. (1973). Should we teach children syntax? Language Learning, 24(2), pp.245-258. http://dx.doi.org/10.1111/j.1467-1770.1973.tb00659.x

Dulay, H. \& Burt, M. (1974). Natural sequence in child second language acquisition. Language Learning, 24(1), pp.37-53. http://dx.doi.org/10.1111/j.1467-1770.1974.tb00234.x 
Duskova, L. (1983). On sources of errors in foreign language learning. In B. Robinett and J. Schachter (Eds). Second Language Learning: Contrastive analysis, error analysis, and related aspects, (pp.215-233). Ann Arbor: University of Michigan Press.

Ellis, N. (2002). Frequency effects in language processing: A review with implications for theories of implicit and explicit language acquisition. Studies in Second language Acquisition, 24, pp.143-188. http://dx.doi.org/10.1017/S0272263102002024

Ellis, R. (1990). Instructed Second Language Acquisition. Cambridge: MA. Basil Blackwell.

Ellis, R. (1997). Second Language Acquisition, Oxford: Oxford University Press.

Gass, S., Torres, A. \& Jose, M. (2005). Attention when? An investigation of the ordering effect of input and interaction. Studies in Second Language Acquisition, Vol.27, No.1, pp 1-31. http://dx.doi.org/10.1017/s0272263105050011

Gass, S.M. and Selinker, L. (2001). Second language acquisition: An introductory course, 2nd ed., Mahwah, NJ: Lawrence Erlbaum Associates Inc.

Gill, S. K. (1993). Standards and pedagogical norms for teaching English in Malaysia World Englishes, 12, pp.223-238.

Goldstein, T. (2001). Researching women's language practices in multilingual workplaces. In Pavlenko, A., Blackledge, A., Piller, I., Teusch-Dwyer, M. (eds). Multilingualism, second language acquisition, and gender, New York: Mouston de Gruyter, pp 77-101. http://dx.doi.org/10.1515/9783110889406.77

Gorokhova, E. (1990). Acquisition of English articles by native speakers of Spanish. Rutgers The State University of New Jersey, New Brunswick.

Govindasamy, S. (1994). The effect of contrastive grammar instruction on clarity and coherence in the writings of Malay ELS college students. Unpublished doctoral dissertation, Rutgers

Ismail, R. (2005). Communication Strategies and Collaboration of Malaysian ESL Learners in Oral Interaction, (Unpublished Phd thesis. Penang: Universiti Sains Malaysia, Malaysia)

James C. (1998). Errors in language learning and use. Exploring error analysis. London: Longman.

Kaur, K. (1995). Why they need English in Malaysia: a survey. World Englishes, 12(2), pp. 223-236. http://dx.doi.org/10.1111/j.1467-971X.1995.tb00351.x

Kramsch, C. (1998). Language and culture. Oxford: Oxford University Press.

Lightbown, P. (2000). Classroom SLA research and second language teaching. Applied Linguistics, 21(4), pp.431-462. http://dx.doi.org/10.1093/applin/21.4.431

Lindstromberg, S. (1991). (Re)teaching Prepositions. English Teaching Forum, 29, pp 47-50.

Loewen, S. (2005). Incidental focus on form and second language learning. Studies in Second Language Acquisition, 27(3), pp.361-384. http://dx.doi.org/10.1017/s0272263105050163

Meyer, J.E.L. (1995). The role of grammar instruction in thematic content-based EAP courses. Guidelines, December, Vol. 1-17, 2, pp.6-10.

Mitchell, R \& Myles F. (2004). Second Language Learning Theories. London: Arnold Hodder.

Mohideen bin Mohamed Ali Haja. (1991). An error analysis in the written English of Malay students at pre-university level. University of Wales, Cardiff, Unpublished doctorial thesis.

Nassaji, H. (2000). Towards integrating form-focused instruction and communicative interaction in the second language classroom: some pedagogical possibilities. The Modern Language Journal, 84, II, pp.241-248. http://dx.doi.org/10.1111/0026-7902.00065

Nassaji, H. (2000).). Grammar in the classroom: findings from research. Language Learning Journal, 19, pp.33-39.

Norris, J.M. \& Ortega, L. (2000). Effectiveness of L2 instruction: A research synthesis and quantitative meta-analysis. Language Learning, 50/3, pp.417-528. http://dx.doi.org/10.1111/0023-8333.00136

Norton, B. (2000). Identity in language learning: Gender, ethnicity and educational change. London: Longman.

Nunan, D. (1992). Research methods in language learning. Cambridge: Cambridge University Press.

Pica, T. (1983). Adult acquisition of English as a second language under different conditions of exposure. Language Learning, 33, pp. 465-497. http://dx.doi.org/10.1111/j.1467-1770.1983.tb00945.x 
Roberts, P. (1995). Why can't form and meaning be friends? The place of grammar in modern English teaching. Guidelines, 17(2), pp.1-8.

Rutherford \& M. S. Smith. (Eds). (1998). Grammar and second language teaching, pp. 46-89 New York: Newbury House.

Ruziah Md. Zain. (2006). Enhancing the correct use of prepositions through error identification drill exercises among the KPLI(M) students. Jurnal IPBA, 3(3), pp 10-15.

Sandra D, \& Rice S. (1995). Network analysis of prepositional meaning: Mirroring whose mind - the linguist's or the language user's? Cognitive Linguistics. Vol.6-1, pp.89-130.

Schmidt R.W. (1990) The Role of Consciousness in Second Language Learning. Applied Linguistics, Vol. 11, pp.129-152.

Schmidt, R. (1983). Interaction, acculturation, the acquisition of communicative competence. In Wolfson, N. and Judd E. (eds). Sociolinguistics and TESOL. PP. 137-174. Rowley, MA. Newbury House.

Schumann, J. (1979). The acquisition of English negation by speakers of Spanish. A review of the literature. In R. Andersen (Ed.) The acquisition and use of Spanish and English as first and second languages pp.3-32. Washington DC.

Selinker, L, J.T. \& Lamendella (1981). Updating the Interlanguage hypothesis: Studies in Second Language Acquisition, 3, 2, pp.201-220. http://dx.doi.org/10.1017/s0272263100004186

Tobin, Y. (1990). Semiotics and Linguistics. London \& New York: Longman.

Wagner, G, \& Weitzman, M.L. (2015) Errors of commission versus errors of omission in The Globalist Columbia University Academic Commons, http://dx.doi.org/10.7916/D81V5DMW

Wong, B.E. \& Chong, S.Y.L. (2006). Non-native grammars: L2 representation of English locational and directional prepositions. In Allan, K. Selected papers from the 2005 Conference of the Australian Linguistic Society. http:au.geocities.com/ austlingsoc /proceedings /als2005/wong-chong-prepositions.pdf.

Zhang, Y, \& Widyastuti, I (2010). 'Acquisition of L2 English morphology: A family case study'. Australian Review of Applied Linguistics, 33 (3), 29.1-29.17. http://dx.doi.org/10.2104/aral1029 